Miami Nature Biotechnology Short Reports

TheScientificWorld (2001) 1(S3), 109SR

ISSN 1532-2246; DOI 10.1100/TSW.2001.122

\title{
PYRROLO-1,5-BENZOXAZEPINES INDUCE APOPTOSIS IN CHRONIC MYELOID LEUKEMIA (CML) CELLS BY BYPASSING THE APOPTOTIC SUPPRESSOR BCR-
} ABL

Margaret M. Mc Gee*, Giuseppe Campiani, Anna Ramunno, Caterina Fattorusso, Vito Nacci, Mark Lawler, D. Clive Williams, Daniela M. Zisterer

Department of Biochemistry, Trinity College, Dublin 2, Ireland

*mmcgee@tcd.ie

INTRODUCTION. Chronic myeloid leukemia (CML), which accounts for 20\% of all leukemias, expresses the transforming oncogene, bcr-abl. Expression of $b c r-a b l$ results in the production of an abnormal tyrosine kinase and is reported to confer resistance against apoptosis induced by many chemotherapeutic agents. Recently a novel series of pyrrolo-1,5benzoxazepines (PBOXs) were synthesised (Campiani et al., 1996) and some of these compounds induce apoptosis in a number of cancerous cells (Zisterer et al., 2000). In this study, a number of these novel pyrrolo-1, 5-benzoxazepines were found to induce apoptosis in CML cells. We examined whether Bcr-Abl becomes downregulated and whether its protein tyrosine kinase activity is altered during apoptosis (Mc Gee et al., in press).

METHOD. Cells were cytocentrifuged onto slides and stained with eosin Y and methyl blue. Apoptotic cells were characterised by cell shrinkage, membrane blebbing, nuclear condensation and DNA fragmentation (Fig. 1). Levels of Bcr-Abl expression, protein tyrosine phosphorylation and PARP cleavage were measured by Western blot. Caspase 3-like protease activity was measured using a substrate, Ac-DEVD-AMC, which is cleaved and fluorogenic AMC released.

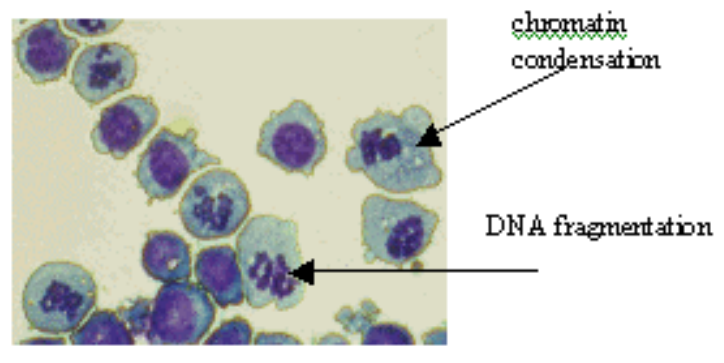

RESULTS. A representative pyrrolo benxozaxepine, PBOX-6, was found to induce 40-50\% apoptosis in CML cells in a time and dose dependent manner (Fig. 2). Downregulation of Bcrabl was not detected and the tyrosine phosphorylation status of proteins was unchanged up to 24 hours following treatment with PBOX-6. Caspase 3-like proteases were activated in K562 
and LAMA 84 cells, but not in KYO.1 cells although apoptosis was induced to the same extent. Pretreatment of cells with a caspase 3-like inhibitor, Z-DEVD-fmk, prior to PBOX-6 inhibited caspase 3-like protease activity, but failed to prevent against apoptosis.

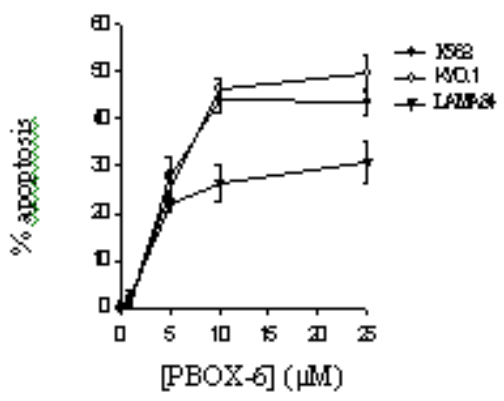

DISCUSSION. We have shown that PBOX-6 is a potent inducer of apoptosis in CML cells and is able to bypass Bcr-Abl mediated resistance. Downregulation of Bcr-Abl did not accompany but rather followed the induction of apoptosis. The tyrosine phosphorylation status of proteins remained unchanged up to 24 hours following treatment with PBOX-6. These results suggest that a reduction in Bcr-Abl expression, or inhibition of tyrosine kinase activity is not the only mechanism by which cells can escape the anti-apoptotic effect of the $b c r-a b l$ gene. Activation of caspase 3-like proteases is not required for the induction of apoptosis by PBOX-6 in the CML cells examined. Results from this study suggest the potential of this compound as a novel anti-cancer agent for the treatment of CML.

ACKNOWLEDGEMENTS. This study was supported by BioResearch Ireland, National Pharmaceutical Biotechnology Centre.

\section{REFERENCES.}

1. Ciampiani, G., Nacci, V., Fiorini, I., DeFilippis, M.P., Garofalo, A., Ciani, S.M., Greco, G., Novellion, E., Williams, D.C., Zisterer, D.M., Woods, M.J., Mihai, C., Manzoni, C., and Mennini, T. (1996) J. Med. Chem. 39, 3435-3450

2. Zisterer, D.M., Campiani, G., Nacci, V., and Williams, D.C. (2000) J. Pharmacol. Exp. Ther. 293, 48-59

3. Mc Gee, M.M., Campiani, G., Ramunno, A., Fattorusso, C., Nacci, V., Lawler, M., Williams, D.C., and Zisterer, D.M. J. Pharmacol. Exp. Ther. (in press) 


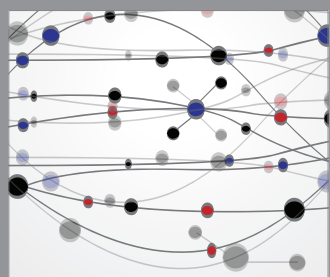

The Scientific World Journal
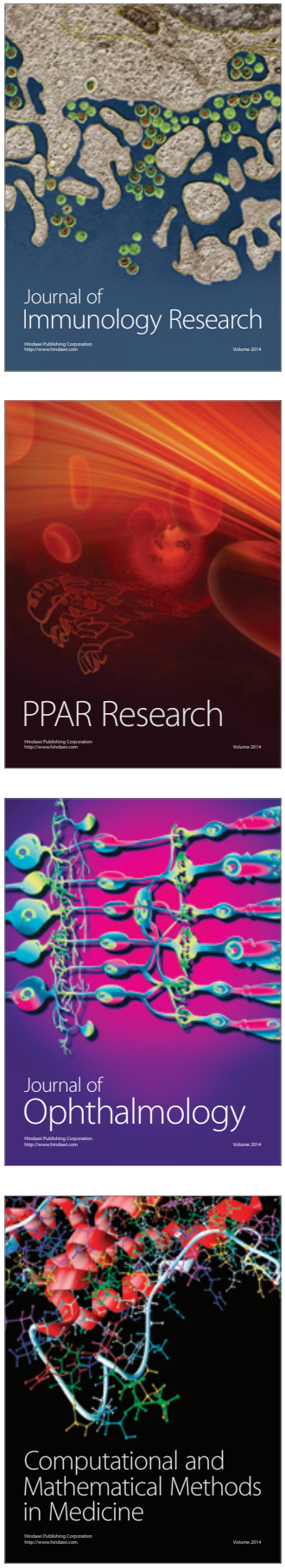

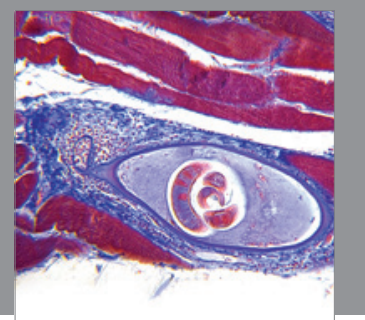

Gastroenterology

Research and Practice
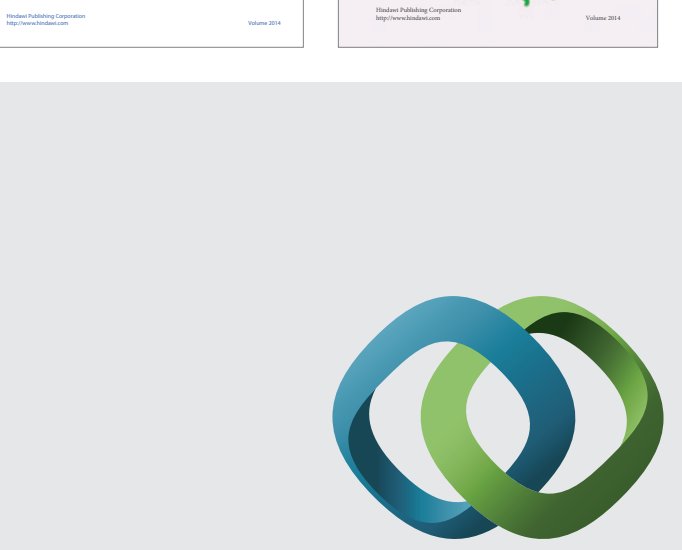

\section{Hindawi}

Submit your manuscripts at

http://www.hindawi.com
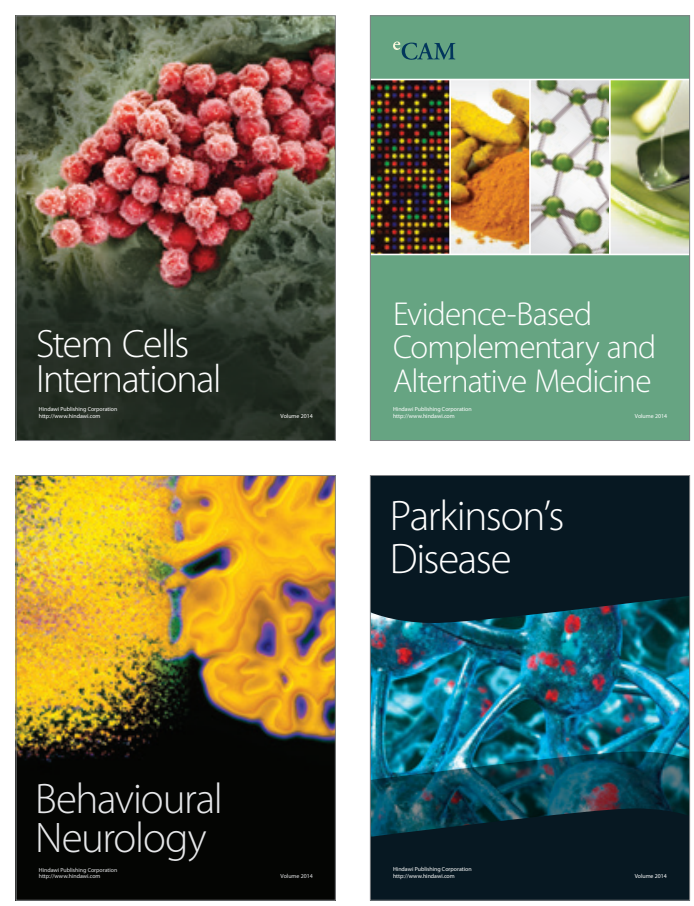

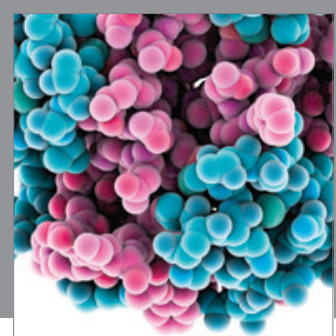

Journal of
Diabetes Research

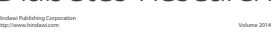

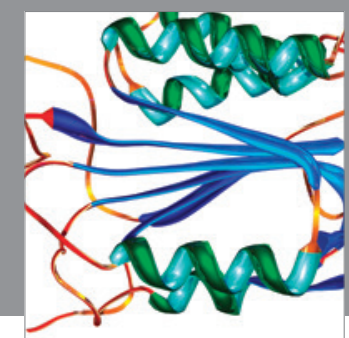

Disease Markers
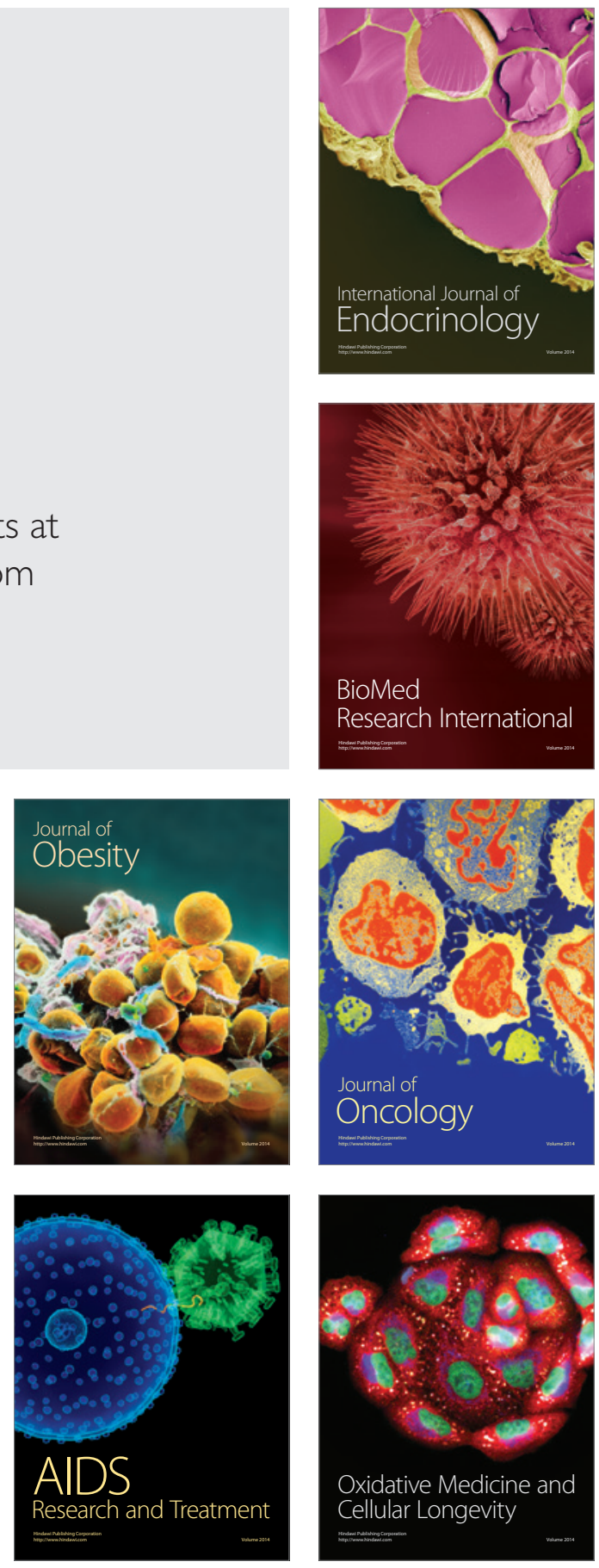